\title{
Pragmatic Concerns and Images of the World
}

\author{
Fernando Birman
}

Received: 22 September 2009 /Revised: 10 February 2010 / Accepted: 11 February 2010 / Published online: 3 March 2010

(C) The Author(s) 2010. This article is published with open access at Springerlink.com

\begin{abstract}
I defend a pragmatist reinterpretation of Sellars's famous manifestscientific distinction. I claim that in order to do justice to this important distinction we must first recognize, despite what philosophers - including, arguably, Sellarsoften make of it, that the distinction does not draw an epistemological or metaphysical boundary between different kinds of objects and events, but a pragmatic boundary between different ways in which we interact with objects and events. Put differently, I argue that the manifest-scientific distinction, in my view, can be best understood, not as a metaphysical distinction between apparent and real objects and events, or an epistemological distinction between perceptible and imperceptible objects and events, but rather as a distinction, which is not necessarily rigid over time, between distinct ways in which we collectively deal, in practice, with objects and events.
\end{abstract}

Keywords Pragmatism $\cdot$ Eliminativism $\cdot$ Manifest image $\cdot$ Scientific image Perceptibles $\cdot$ Imperceptibles

\section{Introduction}

In Maudlin (1997), where some revealing connections between Wilfrid Sellars's philosophy and Bohmian mechanics are investigated, I first came to realize that Sellars's (1962) famous distinction between the manifest and scientific image of (man in) the world is probably of critical, and mostly of unexplored, importance for the philosophy of quantum mechanics. In my view, Sellars's distinction is of special significance with respect to recent discussions, like Albert (1996), of the Correspondence Principle. But its relevance, of course, must not necessarily be restricted to this issue. In this work, however, I will put all quantum-mechanical

F. Birman $(\bowtie)$

Department of Philosophy, Delft University of Technology, Delft, the Netherlands

e-mail: f.a.birman@tudelft.nl 
conundrums aside to defend, perhaps as a tentative prolegomenon to any future quantum metaphysics or epistemology, the viability of (a pragmatist version of) Sellars's distinction itself. More precisely, I will contend that, despite what most philosophers (including, arguably, Sellars himself) make of it, such a distinction can be best understood, not as a metaphysical distinction between appearances and realities, or an epistemological distinction between perceptibles (along with introspectables) and imperceptibles, but rather a distinction between pragmatic ways of dealing with the world.

In "Appearances and Realities", I will present the metaphysical view that is often associated with the manifest-scientific distinction. I will then take issue, in "Two Problems", with this view, as well as its association with the distinction. In "Manifest Image and Scientific Image", some major features of the distinction will be analyzed, which do not necessarily correspond to those originally introduced by Sellars. In "Perceptibles and Imperceptibles", I will set forth the second view, of an epistemological nature, that is usually associated with the manifest-scientific distinction. This view, as well as its association with the distinction, is criticized in "Objections and Examples". In "Pragmatic Concerns, Images of the World", I will offer and discuss my own approach to the distinction, which is pragmatist in nature. Finally, all previous results will be summarized in "Conclusion".

\section{Appearances and Realities}

On a first, and not exactly correct, approximation, we could say that our general picture of the world is formed by the fusion of two distinct worlds: the world of appearances - people, tables, handshakes, the Great Wall of China, Botticelli's Venus and Mars, etc, and our intentional and phenomenal states - and the world of realities - elementary particles, a universal wave function in $3 N$-dimensional configuration space, Planck-length strings in one-dimensional space, and so on. Our most immediate and spontaneous description of the world is based upon the world of appearances. That is the world of our familiar macroscopic objects and events, with which we become immediately acquainted through our senses and reason, and the world of our phenomenal and intentional states. In the Southern Andes, Argentina, there is a big mountain called 'Aconcagua'. Once I happened to visit that region, and I saw a mountain, and I thought (correctly) 'That is the highest mountain peak in the Western Hemisphere'. Now, all this being, seeing, and believing clearly belongs to the world of appearances. All these facts-either natural, phenomenal, or intentional — were apparent to me, and they would also be apparent to any capable individual who took the trouble to go to that place in Argentina. But imagine now for a minute (God forbid!) all humans and animals wiped out of the map. Would there still be this mountain in the Southern Andes? Would the Andes exist at all? Would all of our everyday, familiar, macroscopic objects still be out there? It is fairly obvious - or so it seems - that our particular way of perceiving things (given our poorly fine-tuned sensory systems), and our particular way of experiencing things (given our rough and limited phenomenal capacities), and our particular way of reflecting upon things (given our far from perfect computational capacities) is completely irrelevant for any thorough and objective description of the 
world. If God (say) wanted to make an ultimate list of all the facts of the world at any moment, it seems natural to conclude that He would only include statements about fundamental particles, or strings, or fields, and so on, without any reference whatsoever to how this would look like if some very peculiar observers with such and such sensory, phenomenal, and epistemic capacities happened to be out there, at that exact moment, watching. And so, the argument goes, the real world is this world of particles, or strings, or fields. The other world is just a world of appearances - a "mirage", as David Albert (1996, p. 279), who embraces some version of this argument, has put this. It is the real world as it distortedly appears to some macroscopic beings that, provided their very limited capacities, cannot look at things closely enough.

\section{Two Problems}

There exist at least two critical points that sound suspicious to me in this story. And they make this rendering of the appearances-realities distinction, repeatedly placed by authors at the crux of the manifest-scientific distinction, ${ }^{1}$ dubious. Let us start by looking at what, I believe, is the most obvious difficulty.

It is suggested here that appearances, unlike realities, are a byproduct of human consciousness, which is (most likely ${ }^{2}$ ) beyond the scope of fundamental physics. Consequently, it is suggested, a bit too hastily, that appearances, which may be of profound psychological and neurological interest, are of no relevance to fundamental physics. Arthur Eddington has clearly and wittily presented this view in his famous Two Tables example. He said (1929, pp. ix-xii):

Two tables! Yes, there are duplicates of every object about me-two tables, two chairs, two pens... One of them has been familiar to me from my earliest years. It is a commonplace object of that environment which I call the world. How shall I describe it? It has extension; it is comparatively permanent; it is coloured; above all it is substantial... Table No. 2 is my scientific table. It is a more recent acquaintance and I do not feel so familiar with it. It does not belong to the world previously mentioned - that world which spontaneously appears around me when I open my eyes ... My scientific table is mostly emptiness. Sparsely scattered in that emptiness are numerous electric charges rushing about with great speed; but their combined bulk amounts to less than a billionth of the bulk of the table itself... I need not tell you that modern physics

\footnotetext{
${ }^{1}$ Potter (1994), for example, epitomizes such an attitude by saying: "Wilfrid Sellars thinks that the scientific image is the really real world (the noumenon), while the manifest image is only appearance (the phenomenon)" (p. 15). van Fraassen, along the same line, declares: "To put it bluntly then, the Manifest Image must be regarded as Appearance only, and not as Reality" (1999, p. 32). McDowell (2009, pp. 98-9) likewise: "Sellars thinks the ordinary objects that seem to be present to consciousness in perceptual intuitions are strictly unreal ... What do really exist are the constituents of the scientific image". Karitzis and Psillos go even further and, while criticizing deVries (2005), affirm (2007, p. 557): "Sellars is not just raising doubts about the manifest image. He offers an argument that the manifest image is replaceable by the scientific image".

${ }^{2}$ But $c f$. Wigner (1967) for a contemporary example of Cartesian interactionism.
} 
has by a delicate test and remorseless logic assured me that my second scientific table is the only one which is really there-wherever "there" may be. On the other hand I need not tell you that modern physics will never succeed in exorcising that first table-strange compound of external nature, mental imagery and inherited prejudice — which lies visible to my eyes and tangible to my grasp... "You speak paradoxically of two worlds. Are they not really two aspects or two interpretations of one and the same world?" Yes, no doubt they are ultimately to be identified after some fashion. But the process by which the external world of physics is transformed into a world of familiar acquaintance in human consciousness is beyond the scope of physics.

As Maudlin (1997, p. 7) has observed, there is a suggestion here that these two tables are to some extent in competition, which only one can really survive. The apparent table has to make way for the real table, the scientific one. The triumph of science, as Maudlin puts it, implies the abandonment of the world of common sense. Now, it is evident that a major objection against the appearances-realities distinction on this point would be that the world of appearances cannot possibly be abandoned by science because it is precisely there, in this world, where one finds the grounds for accepting the world of realities. All measuring devices, by definition, are expected to provide apparent macroscopic results, some of which support our inferences about the world of realities. These results must either be seen, or heard, or read on a screen, etc, by some appropriately located observers - or, if you consider something along the lines of the many-minds interpretation of quantum mechanics, these measuring devices are expected to provide, if not definite macroscopic results, at least definite intentional states in the observers. ${ }^{3}$ One cannot possibly eliminate the world of appearances without eliminating, if not the world of realities, at least the very grounds for believing in the world of realities. But eliminating those grounds, I think, entails nothing less than killing the science whose triumph we are trying to advance. ${ }^{4}$

Perhaps we are misrepresenting here this so-called eliminativist position. One might perhaps contend at this point, as Maudlin himself appears to suggest, that the aforementioned elimination is intended to be a metaphysical elimination and not an epistemological elimination. In other words, maybe this elimination should be exclusively viewed as a metaphysical purge of all appearances from the realm of real facts, while we keep trusting such appearances - the idea being that we keep believing in those appearances as, roughly, false proxies of reality. I must say, however, that I find it very hard to make sense of this interpretation. I find it difficult to see, that is, how to have metaphysical elimination for dinner without having, as it were, epistemological elimination for dessert. It is difficult to see, in other words, how to ascribe at all epistemic credit to that to which we not only deny reality but

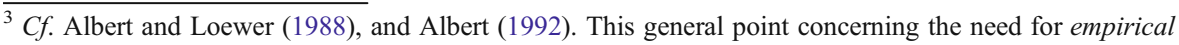
inputs does not necessarily entail, of course, falling back to a foundationalist conception of the "given", which Sellars (1956) so artfully criticized.

${ }^{4}$ This line of reasoning could certainly be recast in the form of a transcendental argument, in the sense that it puts forward necessary conditions for the very possibility of that which the believer in science takes for granted. I want to thank one of the anonymous referees for underscoring this point to me.
} 
also, as a matter of principle, verisimilitude. ${ }^{5}$ But even if, notwithstanding this, we acquiesced to believe that metaphysical elimination does not entail epistemological elimination, there would be still plenty of room to wonder where the "privileged" epistemological status of genuine appearances (like, for instance, the pointer of a Stern-Gerlach device pointing at $x$-spin up) as opposed to fake appearances (like dreams and hallucinations) comes from once the metaphysical elimination has done its job. The problem here, simply put, is that metaphysical elimination leaves all appearances, both genuine and fake, in exactly the same fictional state-which seemingly entails that some appearances must be, somehow, a little less fictional than others. And this is why also, in my view, entertaining metaphysical elimination without epistemological elimination is an extremely perplexing philosophical stake. It is difficult to see, again, where the epistemological import of genuine appearances - which, as noted, constitute our grounds for believing in a world of realities to begin with - comes from after metaphysical elimination has taken place. It is, however, something along these lines what advocates of the realitiesappearances distinction, like Eddington and Albert, ${ }^{6}$ have apparently in mind when they speak of the unreal, even deceitful, character of appearances.

There is still, however, a more robust and, perhaps, conclusive objection against the viability of the distinction. It goes like this. The realities-appearances distinction, as presented, takes for granted a categorical difference between the terms of the distinction. Simply put, appearances and realities are two different kinds of things. Appearances, in this perspective, are observer-dependent. They emerge in virtue of our particular sensory, phenomenal, and epistemic capacities - and even perhaps our social, economic, and cultural environments as well. As Eddington voices this, appearances are a "strange compound of external nature, mental imagery and inherited prejudice". Realities, in contrast, are not observer-dependent. Their description, according to this perspective, does not involve any reference whatsoever to how things appear to us. Realities do not manifest, as it were, any human mark. This is rather how things would appear if God, with his particular view from nowhere, cared to look. Now, what strikes me as definitely curious about this view is that, despite its clear merits as a guideline or heuristic inspiration, it is now known to

\footnotetext{
${ }^{5} \mathrm{I}$ believe a similar degree of puzzlement is behind Wallace and Timpson's reaction to this eliminativist stance. They say: "While the [eliminativist] will deny that three-dimensional objects and spatial structures find a place in the fundamental ontology, this is not to say that the three dimensional objects surrounding us, with which we constantly interact, and which we perceive, think and talk about, do not exist; that there are not truths about them; it is just to maintain that they are emergent objects, rather than fundamental ones. But an emergent object is no less real for being emergent" (2009, p. 8). And Monton (2006), along similar lines, observes that "... our everyday understanding of the world is not simply that the world appears to us to have objects evolving in three-dimensional space ... [but rather that] the world does have objects evolving in three-dimensional space" (p. 784).

${ }^{6}$ This eliminativist stance is widespread among physicists, like the two authors mentioned here. But there are of course very notable exceptions-Richard Feynman is probably such a case ( $c f$. Feynman 1999). It must be acknowledged, however, that Albert seems a little less prone to eliminativism in (2000), where he declares (p. 1): “... a list of what particles exist, and what sorts of particles they are, and of what their positions are at all times, is a list of absolutely everything there is to say [in a Newtonian world] about the physical history of the world ... this is certainly not to deny that there are such things in the world as extended objects; the idea is just that all the facts about objects like that (facts about where the tables and chairs are, and about who punched whom, and about who said what) are determined, in principle, by the facts about the particles of which those objects are composed".
} 
be false. More exactly, and regardless of whether we favor a realist or constructivist view of science, the external essentialism that transpires from the perspective is now largely discredited. The relevant debate is no longer centered on whether our description of the world is a mirror-image of transcendent, ahistorical, incontestable events, but rather on the extent to which such description can be subjected, or not, to the objective test of an independent reality - a reality that exists on its own. ${ }^{7}$ It is hard to see then how to set up at all a categorical difference between the terms of this distinction-or, more exactly, between what these terms stand for here: a description of the world based on the language of fundamental physics and, alternatively, a description of the world in terms of our everyday language of people, tables, handshakes, etc. It is evident, on the contrary, that there is only a gradual difference between what these terms represent, where appearances and realities correspond to different images of one and the same real world, arising from differentin depth, range, and accuracy-explanatory and predictive interests and concerns. Appearances and realities, if we stick to these terms, reveal both the human mark. They both arise in virtue of our sensory, phenomenal, and epistemic capacities - and, if some form of social constructivism is correct, "the concerns of the age" (Kitcher 2001 b, p. 82). They both incarnate, in sum, views from somewhere.

\section{Manifest Image and Scientific Image}

Before proceeding to what, accordingly, will represent a far less perplexing and more appropriate distinction, that between two alternative images of one and the same world, it is worth pausing for a moment to dismiss one possible objection or misunderstanding regarding what has just been presented. It could be argued at this point - mistakenly, I believe - that a rejection of the appearances-realities distinction as presented boils down to the following (sort of) Kantian move: the blending of our manifest and scientific worlds now represents an epistemically accessible though subjective and context-dependent phenomenal world, and we posit beyond that an epistemically inaccessible world, a noumenal world, a real and objective world of which the aforementioned phenomenal world is, in some unclear sense, a distortion. ${ }^{8}$ I believe this would be a misrepresentation of what has just been presented. Both our manifest and scientific depictions of the world display, as argued, the human mark, and accordingly they represent, in Nagel's terms, a view from somewhere. ${ }^{9}$ This

\footnotetext{
${ }^{7}$ Contemporary supporters of scientific realism are ready to distance themselves from what is customarily referred to as scientific essentialism-Niiniluoto (1987); Boyd (1990, 1999); Lipton (1991); Weston (1992); Kitcher (1993, 2001a); Worrall (1994); Psillos (1999). And contemporary supporters of scientific constructivism are also, of course, ready to condemn scientific essentialism-Kuhn (1957, 1970); Latour and Woolgar (1979); Pickering (1984); Galison (1987); Latour (1987); Collins and Pinch (1993); Kitcher (2001b).

${ }^{8}$ The subjectivity and context-dependency of this phenomenal world would not, of course, be Kantian in nature. And Kant would not consider it a "distortion" of the noumenal world.

${ }^{9}$ It is worth emphasizing here that this scenario does not exclude in any way the possibility of objectivity, or in Parfit's words, later adopted by Nagel, agent-neutral reasoning_Parfit (1984); Nagel (1970, 1986). Nagel's own extensive work on this issue clearly suggests that the abandonment of essentialism does not necessarily bring about the demise of objectivity, either in the realm of morality and law or the realm of scientific inquiry here discussed.
} 
does not entail, nevertheless, that there is some ultimate, inaccessible, viewed-fromnowhere world beyond those different descriptions, a world that can only be captured in some primordial God-created language. Put differently, there is no noumenal world that, by definition, cannot be known but only conjectured, if at all, in our phenomenal world. This, I think, amounts to an unsustainable hypostatization. Our manifest and scientific worlds are two different images of the real world, just like (say) spotting an island from a distance (if you are, for example, on a cruise in the Caribbean) and walking on that island's beaches and through the woodland provides you with two different images of the island. Following this example, I cannot begin to imagine what a noumenal, transcendent island waiting to be seen by a God-like creature from a nowhere perspective could possibly amount to. There are, I think, only different views or perspectives of the island, which can of course serve different interests and purposes-depending on whether you happen to be interested in skydiving, mapping the coast line, looking for new bird species, or what have you. ${ }^{10}$ Some of these perspectives might even be deceitful, leading you to false beliefs about this place. You might think, for instance, that that is not an island at all, but just a peninsula. And you could easily learn the truth after further examination - say, after walking around the island, or after looking at a satellite map of the island, and so on. But, again, it is rather hard to imagine how one could possibly make sense of the idea that, beyond all the different images of this place, there might be a primordial, perspective-independent, real view of the island, some kind of noumenal island that-somehow-supports all these images while systematically differing from each and every one of them. It is hard to imagine what that island-if that is still the right name for it - could possibly amount to.

We are now stepping on Sellars's distinction-or, more exactly, my own reinterpretation of the distinction: I will not present what follows as an exegesis of Sellars's own view of the distinction, or his historiographical motivations for introducing such a distinction. ${ }^{11}$ Our overall picture of the world is the result of a fusion - or juxtaposition - of our manifest image of the world and our scientific

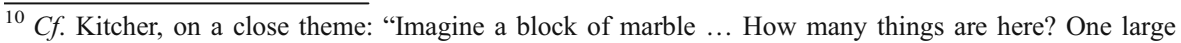
block of marble, of course, but the question is notoriously ill posed. For there are many different lumps of marble inside the big block, many potential statues waiting to be released. Let's restrict our attention to statuesque representations of David. There are pieces of marble that take the shape of Bernini's version, of Michelangelo's, and of Donatello's ... and there are as many of each as we can distinguish different sizes ... The marble is a little piece of the world, and ... it can be conceived as divided up into objects in many different ways ... those objects, those chunks of marble, exist. We draw (or chisel) the lines, but we don't bring the chunks into being" (2001b, pp. 44-5).

${ }^{11}$ Sellars's distinction is - famously - introduced to pinpoint two opposing, and conflicting, idealized poles in the history of Western philosophy. One of the poles encompasses people, with their phenomenal, intentional, and normative dimensions. And the other pole concerns the natural sciences' laws and ontology, which are constantly refined throughout science's asymptotic progress. The ultimate aim of philosophy, according to Sellars, is to bring these two poles together by means of synoptic "stereoscopic" view of (wo)man-in-the-world. For influential accounts and discussions of Sellars's philosophy, into which we will not further delve here, $c f$. van Fraassen (1976, 1999); Aune (1990); McDowell (1994, 2009); Brandom (1995, 2002); deVries (2005).
} 
image of the world. These two images involve distinct, and often inconsistent, ${ }^{12}$ descriptions of the world. There has to be points of contact, however, so that we can routinely say things like, for example: 'Spin-1/2 particle $x$ is up because the pointer of this measuring device is pointing at $u p$ '. The manifest image is where we spontaneously find ourselves - our bodies and our mental states - along with all other everyday objects, properties, and events, and a more or less unspecified set of causal relations. The scientific image, in contrast, brings new and mostly unfamiliar objects, properties, and events, and an array of highly specific causal relations. It is incorrect, as I have just argued, to equate the manifest image with a world of appearances and the scientific image with a world of realities. Both images are observer-dependent. This means that they both involve a view-from-somewhere perspective. And both images are real images of the world. ${ }^{13}$ There is no reasonable ground, consequently, for introducing a categorical distinction between these terms. Moreover, there exists no noumenal world of which these images are, somehow, a distortion. What are these images then images of? They are images of the real, objective world. No transcendent, viewed-from-nowhere world is necessary to make sense of these two images, just like no transcendent, viewed-from-nowhere island is necessary to make sense of all the ever changing perspectives of the island. This demand for an ultimate, perspective-independent object supporting all the different images of it, but which is not an image itself, involves, I think, a subtle philosophical myth-following Quine, we might call it the myth of the inscrutable object. It maintains that some transcendent noumenal object is a necessary condition for us having different images of an object. This myth (which Husserl examined in detail, although with a different philosophical agenda in mind) is behind the objection discussed one paragraph above. ${ }^{14}$ Now, new images of the world may naturally supersede old images, both manifest and scientific. Or, maybe more accurately, parts of old images may be replaced with new images. A manifest image where a dream is an oracle of future events - like in Gilgamesh's tale-has been unceremoniously replaced with a manifest image where dreams are distorted reflections of the past. A manifest image where rain is Uranus's urine - as Hesiod reports - has been replaced with a manifest image where rain is a relatively straightforward meteorological event. In the same way, as historians of science have eloquently shown in the last

\footnotetext{
${ }^{12}$ As Eddington observes, the manifest table is substantial but the scientific table is mostly empty space. This inconsistency would be even more severe if we considered, for example, a quantum-mechanical description of the world where, say, the single entity of the world is the universal wave function evolving deterministically in line with Schrödinger's equation in $3 N$-dimensional configuration space, where $N$ is a colossal number, or a description that takes one-dimensional Planck-length vibrating strings as the fundamental blocks of reality.

${ }^{13} \mathrm{I}$ believe it is interesting to note here that Sellars himself, despite prevailing agreement to the contrary, appears at times to embrace this point. For example, he says (1963, p. 5): "By calling them images I do not mean to deny to either or both of them the status of reality. I am, to use Husserl's term, bracketing them, transforming them from ways of experiencing the world into objects of philosophical reflection and evaluation".

${ }^{14}$ It is also a rejection of this myth what likely inspires Putnam's famous criticism of what he called "metaphysical realism", an externalist type of realism, and his postulation instead of an internalist variation of the realist theme, his so-called "internal realism" — cf. Putnam (1978, 1981, 1983). Analogously, a rebuttal of the myth is likely behind A. Fine's "natural ontological attitude"-Fine (1984, 1986, 1996). My gratitude goes out to one of the referees for underscoring the Putnam connection.
} 
couple of decades, our contemporary scientific image is notably different from that of Aristotle, Galen, Buridan, Newton, Herschel, and Mendel, to name just a few. These new images are of course more refined-in terms of explanatory and predictive power - than the old images. And it is likely, unless we had reached a point in history where we know everything, or nearly everything, there is to know about the world (this possibility, however, is not obviously false ${ }^{15}$ ), that new and more refined images will in time supersede our present images as well.

\section{Perceptibles and Imperceptibles}

So far I have tacitly adhered to an intuitive criterion for what might be counted as manifest and scientific, taking for granted that some simple claims about rain and dreams belong to the manifest image, and that claims about wave functions, neutrinos, etc, would naturally belong to the scientific image. It is worth trying at this point to flesh out this intuition, so as to make the distinction more precisewhich, as we shall see in a minute, is harder than it looks. Sellars's distinction, as originally rendered, is not a distinction between a pre-scientific image of the worldthe world "as it strikes us on first acquaintance" (Maudlin, p. 6) ${ }^{16}$-and a scientific image of the world. It is not, accordingly, a distinction between some primordial or original image of the world, the world as it might have presented itself to prescientific cultures, and the scientifically advanced image of present-day physics. It is rather a distinction between an image of the world completely shorn of theoretical posits, though maybe enriched by scientific content, and an image of the world which engages, in Sellars's words, imperceptible objects and events. He says (1963, p. 19):

It will be remembered that the contrast I have in mind is not that between an unscientific conception of man-in-the-world and a scientific one, but between that conception which limits itself to what correlational techniques can tell us about perceptible and introspectable events and that which postulates imperceptible objects and events for the purpose of explaining correlations among perceptibles... Our contrast, then, is between two ideal constructs: (a) the correlational and categorical refinement of the 'original' image, which refinement I am calling the manifest image; (b) the image derived from the fruits of postulational theory construction, which I am calling the scientific image.

\footnotetext{
${ }^{15}$ We might be getting closer, as Weinberg (1994) has put it, to the final theory, so that all prior theories will be only partial, even perhaps mistaken, images ultimately encompassed by the final theory. Sellars himself seems to be open to this possibility, which is seemingly why he often refers to the scientific image as the asymptotic Peircean image. It remains to be seen, however, whether all non-fundamental theories (those theories of, to mention three recurrent examples, economics, psychology, and biology) would be reducible to such final and encompassing theory of fundamental physics. It remains to be seen, that is, whether the laws and ontology, and even perhaps the methods, of all non-fundamental theories could be shown to be translatable (through identity, realization or supervenience statements, or some other maneuvers we have not yet thought of) into the language of the ultimate fundamental physical theory — $c f$. Nagel (1961); Fodor (1974, 1997); Kitcher (1984); Dupré (1993).

${ }^{16}$ We might yet wonder if the world as it strikes $u s$, individuals, on first acquaintance does so prescientifically - newborns nowadays get at once to interact with all sorts of technical stuff. But Maudlin is surely referring to our first acquaintance with the world as a species.
} 
Thus, Sellars's distinction - simply put-is a distinction between the perceptible (and introspectable) part of the world, which includes scientific content, and the theoretical part of the world, which comprises imperceptible objects and events postulated in order to explain correlations among perceptibles.

The perceptible-imperceptible distinction has been-famously - the target of many severe attacks since the 1950's. I believe most of these attacks, some of which were conducted by Sellars himself (see, for example, 1956 and 1962), are justified. Sellars's association of the perceptible-imperceptible distinction with his much more interesting manifest-scientific distinction, even if we leave aside our present reinterpretation of the distinction and consider it from Sellars's own historiographical perspective, was probably just an inertial philosophical move. In "Objections and Examples", I will set aside the arguments against the perceptible-imperceptible, or observation-theory, distinction that have been broadly treated in the literature to concentrate instead on just a few simple objections against this specific use of the distinction. I will show, through some modest but straightforward examples, that we will have to look somewhere else for a criterion that can effectively tell us - if we are indeed interested in Sellars's distinction - what is manifest, what is scientific, and what is not.

\section{Objections and Examples}

Let us suppose, to begin with, that "imperceptible objects and events" stands for something like this: objects and events whose presence can only be detected via indirect means. Imperceptible objects and events are objects and events that can exclusively be seen-either literally or metaphorically-with the help of modern technology. "Literally" entails here that the observer can actually see the object in question - we can literally see, for example, eukaryotic cells with some small optical microscopes. "Metaphorically" means here that the observer cannot truly see the item in question but merely infer its presence from the outcome of some measuring device - we can metaphorically see alpha and beta radiation with any inexpensive Geiger counter. It is not without reason to suppose that Sellars may have had something like this in mind regarding these "imperceptible objects and events". ${ }^{17}$ Now, this specific version of the perceptible-imperceptible distinction makes the

\footnotetext{
${ }^{17}$ Sellars was never entirely explicit concerning the meaning of the word "imperceptible". The prevailing opinion holds that, for Sellars, perceptible or observational objects or events are objects or events of which we can have non-inferential knowledge, while imperceptible objects or events are those which can only be known inferentially. If this is so, it seems that objects or events whose presence can exclusively be detected via indirect means are indeed imperceptible, regardless of whether that detection is literal or metaphorical. But Brandom (2002) presents a much subtler version of Sellars's stance on the perceptibleimperceptible distinction. According to Brandom, Sellars believes that theoretical entities can at times be perceptible. He affirms (p. 362): "To be observable is just to be noninferentially reportable. (...) In this sense, physicists with the right training can noninferentially report the presence of mu mesons in cloud chambers. In this sense of 'observation', nothing real is in principle beyond the reach of observation". Although there is a very compelling intuition, which will be exploited later, behind Brandom's interpretation - namely, that theoretical entities can be pragmatically dealt with differently by different individuals, I believe that his conclusion is quite unpalatable. Leaving aside the question of whether this is indeed what Sellars had in mind, Brandom's contention that (p. 363) "If mu meson is the concept the physicist applies noninferentially, then if he is sufficiently reliable, when correct, that is what he sees" looks to me to be false, and probably refuted by a majority of physicists if we cared to ask.
} 
manifest-scientific distinction that is here associated with it the target of some very perplexing examples. Let us consider the following. According to this criterion, the near side of the Moon (i.e., the lunar hemisphere facing Earth) belongs to the manifest image of the world, while the far side of the Moon (the hemisphere continually turned away from Earth) belongs rather to the scientific image. The reason is simple. The far side of the Moon can only be seen with the help of (say) photographic cameras used in the Apollo mission. This conclusion-namely, half of the Moon belongs to the manifest image while the other half is scientificcontradicts, I think, a simple and uncontroversial intuition regarding a familiar object like the Moon. More precisely, it contradicts the intuitive idea that the Moon, despite the fact that we can only observe, in familiar conditions, its near side, is a homogeneous item. ${ }^{18}$

But we are probably misrepresenting the criterion here. It may be enough for some objects and events to have been directly seen by at least some people, like certain astronauts in the Apollo mission, to count as perceptible - so that the far side of the Moon would now belong to the manifest image too. But, leaving aside all questions about public corroboration, it seems odd to maintain that the far side of the Moon did not belong to the manifest image before 1968 (the first lunar orbit) and that the Apollo mission did actually change that. ${ }^{19}$ And, even if we decided, in spite of this observation, to take this point seriously, it is evident that those astronauts needed all the technology behind the Apollo mission to see first-hand that side of the Moon. So this would not count, given the formulation above, as direct observation either.

This very last argument, incidentally, stresses an important fact. Perhaps our original formulation should state that "with the help of modern technology" requires that, for all imperceptible objects and events, certain pieces of modern technology must be immediately involved in their detection, leaving aside those pieces of technology that are not thus involved. In the preceding example, even though it is the technology behind the Apollo mission what made the first lunar orbit possible, that technology was not, in a sense, immediately involved, like an optical microscope while inspecting eukaryotic cells or a bubble chamber while trailing the trajectory of charged particles, when one of the astronauts decided to look outside and saw firsthand the far side of the Moon. Unless one made such a provision requiring immediacy in connection with the relevant application of a piece of modern technology, one could trivially argue, for example, that Iceland belongs to the scientific image of the world-which, I presume, is not the case-given that, excluding native Icelanders, we all need airplanes, ships, submarines, or whatever other piece of modern equipment you can think of, to get there and see the place

\footnotetext{
${ }^{18}$ A similar point could be made regarding, for instance, the seabed. It is directly detectable near the coast line, but otherwise only detectable with the help of modern technology.

${ }^{19}$ Arguing that the far side of the Moon was always in principle directly detectable, though never directly detected before 1968, will not solve this problem either. The very idea of "in principle directly detectable" is indeed extremely elusive. Wittgenstein famously believed, for example, that human trips to the Moon, and thus a direct detection of its far side, would defy "our whole system of physics" (1969, §108). To avoid this gaffe, we might classify a quark as in principle directly detectable, for some day we may learn how to get that small.
} 
first-hand. But the problem here is that, if you come to think about this, it is not at all obvious what a general definition of immediate detection - as opposed to something like intermediate steps-would look like. The problem, to put it slightly differently, is that no general demarcation between what does and does not count as a piece of technology immediately involved in the detection of imperceptibles is available. But without such delineation there is no compelling distinction between perceptibles and imperceptibles, for some items like Iceland would count as imperceptible. And without such distinction there is, according to this approach, no distinction between the manifest and scientific images. ${ }^{20}$

The moral here is this. Our analysis with regard to "imperceptible objects and events" revealed some objectionable consequences for this interpretation of the manifest-scientific distinction. Moreover, it showed that, even if we decided to ignore these consequences, it would be difficult to see how one could provide a general delineation that unambiguously determines what counts as perceptible and imperceptible and, accordingly, as manifest and scientific. This may not be, by itself, a fatal argument against a perceptible-imperceptible distinction. But is this enough reason for rejecting any association of the perceptible-imperceptible distinction with the manifest-scientific distinction? We will consider one further point.

Perhaps "imperceptible objects and events" refers to those imperceptible objects and events of the world whose presence can exclusively be detected via properly indirect means. If so, imperceptible objects and events can exclusively be seen, now just metaphorically but not literally, with the help of some piece of modern technology. The far side of the Moon would now be manifest - it can be literally seen in pictures, video recordings, and so forth. An electron traversing a magnetic field, or a scattering beam of protons just fired at some heavy nucleus, would keep falling, as expected, under the scientific image. ${ }^{21}$ But new problems would soon arise. First, some instances of the application of this criterion would still be problematic. Some large proteins would allegedly belong to the manifest image, given that they can be literally seen with electron cryo-microscopes. And the same would go for some remote parts of the universe, which can be literally seen with (say) the SALT or VLT telescopes. Secondly, there is a new pressing issue here. It concerns the question - which is now relevant, though it was not so before - of how to give an entirely precise, and not merely intuitive, definition of what it means to either literally or metaphorically see something, given that the manifest-scientific distinction now hinges on this distinction. I held before that one can literally see eukaryotic cells with a small optical microscope (and some large prokaryotic cells as well) while one can metaphorically see alpha and beta radiation with a cheap Geiger counter (and some gamma radiation with a more expensive one). But what is

\footnotetext{
${ }^{20}$ We put aside here the problem of determining with precision what counts as modern and technology in "modern technology", which is indeed quite difficult to pin down. Measuring sticks, scales, and clocks would probably not qualify. What about litmus paper, barometers, and optical telescopes?

${ }^{21}$ van Fraassen seems to support this variation of the perceptible-imperceptible distinction. He says (1980, pp. 16-7): “A look through a telescope at the moons of Jupiter seems to me a clear case of observation ... But the purported observation of micro-particles in a cloud chamber seems to me a clearly different case ... while the particle is detected by means of the cloud chamber, and the detection is based on observation, it is clearly not a case of the particle's being observed".
} 
precisely the difference between the former kind of seeing and the latter kind of seeing? How ostensibly, to put it differently, should we see something so as to legitimately say that we can literally see that? Or how distinctly should we see, for instance, a microorganism so as to legitimately say that we can literally see it? The problem here, of course, is whether it is possible to draw a precise, unambiguous boundary between what it means to literally and metaphorically see something. And I am not alone in taking this to be extremely implausible. ${ }^{22}$ It seems rather clear, on the contrary, that these two concepts, just like the concept of immediacy before, do not admit any general, objective, non-arbitrary delimitation.

I have been stressing for the last few paragraphs that the option, which is recurrent among some authors, of correlating the manifest-scientific distinction with the perceptible-imperceptible distinction is, at best, a dubious philosophical choice. This association brings us numerous problems and scarcely any benefits. I will offer here, to conclude, a possible new approach to the issue.

\section{Pragmatic Concerns, Images of the World}

I believe, in a word, that the manifest-scientific distinction stands for pragmatic differences in our collective dealings with the world. I claim, therefore, that the distinction does not represent, contrary to what the two interpretations discussed so far in this paper suggest, either epistemological or metaphysical differences. ${ }^{23}$ Concerning the former, we have just seen that the manifest-scientific distinction cannot be equated with an epistemological distinction between perceptibles and imperceptibles. Regarding the latter, I argued before that the manifest-scientific distinction does not amount to a metaphysical distinction between appearances and realities. I believe, however, that this distinction reflects, in a rather natural and pervasive way, distinct pragmatic attitudes regarding the world. Differently put, there is a fairly general and univocal correspondence between the manifest-scientific distinction and the way in which people ordinarily and spontaneously interact with the world.

This is what I mean. We must observe, firstly, that this distinction is not objective. Different individuals may legitimately draw the line between what is manifest and what is not across different regions of reality. And we must notice, secondly, that this

\footnotetext{
${ }^{22}$ Even someone who defends the legitimacy of some observable-unobservable distinction, like van Fraassen, acknowledges its final, and seemingly unavoidable, arbitrary nature. He says (p. 16): "The problem is: where shall we draw the line between what is observable and what is only detectable in some more roundabout way? Granted that we cannot answer this question without arbitrariness, what follows? That 'observable' is a vague predicate".

${ }^{23}$ It is worth observing that Brandom, going against the prevailing view among interpreters ( $c f$. fns. $1 \& 13$ ), presents Sellars's distinction, not as a metaphysical distinction, but rather as an epistemological (or, as he puts it, methodological) distinction. He says (2002, p. 362): “... according to Sellars's view, the distinction between theoretical objects and observable objects is methodological, rather than ontological ... theoretical and observable objects are not different kinds of thing. They differ only in how we come to know about them". On the exegetical front, Brandom is probably right: Sellars's association of the manifest-scientific with the perceptible-imperceptible distinction seems to support that view. But on the realm of reinterpretation that we pursue here, I claim that both metaphysical and epistemological approaches to the distinction are unsatisfactory.
} 
distinction is not rigid. Even for one and the same individual, the manifest-scientific distinction may change over time, provided the constant and evolving dialectic interplay between the images. ${ }^{24}$ Regarding the first point, what is manifest for a microbiologist does not, of necessity, have to be manifest for a physicist, or a geologist. The boundary between both images can be drawn across different regions of reality depending on different psyches, backgrounds, and practices. Concerning the second point, an individual's ongoing education, along with the occurrence of new scientific and technological discoveries, may alter how the distinction is instantiated for that particular individual at different times. It clearly follows from these two points that there is, strictly speaking, no unique manifest and scientific image of the world, but rather a vast multiplicity of images, both manifest and scientific. $^{25}$ These multiple images share, however, some rather general and common grounds. And hence we label such multiplicity of images the manifest image of the world and the scientific image of the world. And it is this collective sense of the distinction between a manifest and scientific image of the world, which transcends the eccentricity of individual dichotomies, what, in my view, is of great interest for the philosophy of science - and, as said at the outset, for the philosophy of physics as well. ${ }^{26}$ And, again, the difference between the images is not epistemological or metaphysical, but pragmatic. More precisely, the difference between the two images does not rest on the perceptible nature of manifest objects and events and the imperceptible nature of scientific objects and events, or on the apparent nature of manifest objects and events and the reality of scientific objects and events, but rather on the particular manner in which we pragmatically deal, collectively, with those objects and events.

Now, what is exactly the difference between the particular way in which we collectively deal with manifest objects and events and scientific objects and events? That is: What is exactly the difference between our pragmatic behavior, not necessarily as isolated individuals but as collections of individuals, in so far as the manifest and the scientific is concerned?

One plausible way of putting our finger on this goes as follows. Manifest objects and events, unlike scientific objects and events, make a difference in our practical

\footnotetext{
${ }^{24}$ As noted before ( $c f$. fn. 17), Brandom's interpretation stresses the fact that the boundary between manifest and scientific facts is not rigid. He says (p. 363): "the line between things to which we have only inferential cognitive access [i.e., the scientific] and things to which we also have noninferential cognitive access [the manifest] can shift with time, for instance as new instruments are developed". I think the intuition behind this assertion is correct, but Brandom (and allegedly Sellars) incorrectly associates it with an epistemological, based on a fluid observable-unobservable distinction, rather than a pragmatic distinction.

25 The idea of a vast multiplicity of images is not new. See, for example, Donagan (1975). However, this author still correlates the manifest-scientific distinction with a version of the observable-unobservable distinction, and he then criticizes Sellars for failing to notice that some "manifest" images involve objects or events (like supernatural beings and paranormal phenomena) that are not "observable".

${ }^{26}$ Maudlin (1997) affirms, in this vein, that the manifest-scientific distinction, unlike other distinctions pervading the history of "interpretations" of quantum mechanics (macroscopic-microscopic, classicalquantum-mechanical, irreversible-reversible, empirical-theoretical), manages to secure the loose "isomorphism" existing between manifest and scientific facts, which makes this distinction, at least in principle, suitable for approaching the well-known macro-objectification problem within this theory.
} 
actions and decisions. ${ }^{27}$ In other words, manifest objects and events are typically part of the more or less unspecified set of causal relations that governs, as observed in "Manifest Image and Scientific Image", our everyday societal lives. People, tables, handshakes, Aconcagua, rain, dreams, toothache, spaghetti, Iceland, the Great Wall of China, Michelangelo's David would paradigmatically belong to the manifest image of the world, along with all our phenomenal and intentional states associated with them. Gauge invariance, one-dimensional Planck-length vibrating strings, wave functions, p-branes, black holes, weak force, the intrinsic angular momentum of pi mesons, beta decay would paradigmatically belong to the scientific image of the world. Some or all of these items may be manifest for some individuals ${ }^{28}$ but we are now considering the manifest and scientific images, as just argued, as the fusion or juxtaposition of what most people - and the precise scope of "most" is, of course, also fluid over time - happen to regard, in practice, as either manifest or scientific.

There are of course plenty of borderline cases. It seems to me that DNA, Escherichia Coli, radioactive emissions, the Moon would belong to the manifest image of the world: people routinely take DNA tests, stop eating spinach due to possible contaminations, wear special garments near Chernobyl in Ukraine, look up at the Moon to set up Sukkot holidays, and so forth. It is likely, though, that 50 years ago DNA belonged to the scientific image of the world, precisely like radioactive emissions and E. Coli-before Becquerel, the Curies, Rutherford and Escherich, respectively, made public their discoveries in matters of radioactive decay and bacteriology - in the last decade or so of the nineteenth century.

As noted, this is but one plausible way of nailing down what constitutes the key pragmatic difference between the manner in which we collectively deal with manifest and scientific objects and events. Other ways, even perhaps more distinctive, may certainly be found.

\section{Conclusion}

The moral here, very briefly, is the following. In order to do justice to Sellars's manifest-scientific distinction, which is of consequence for both philosophers of

\footnotetext{
${ }^{27}$ This clearly follows the spirit of the famous so-called "pragmatist maxim", and thus the pragmatist, as opposed to metaphysical or epistemological, nature of our overall approach to Sellars's distinction. This maxim, whose first formulation is generally credited to Peirce (1878), finds its most popular exposition in James (1907). He says (p. 45): "The pragmatic method ... is to try to interpret each notion by tracing its respective practical consequences. What difference would it practically make to any one if this notion rather than that notion were true?" And a little later (p. 50) he adds his famous "no difference in abstract truth that does not express itself in a difference in concrete fact and in conduct consequent upon that fact". Regardless of whether we favor the pragmatist theory of truth implicit here, which is not directly related to the maxim's goal of elucidating concepts (or, as Peirce says, making our ideas clear), it is the maxim's emphasis on the practical/behavioral consequences of our conceptual distinctions what, I claim, lies at the core of the manifest-scientific distinction.

${ }^{28}$ This is likely what the so-called new experimentalists, like Hacking and Cartwright, have in mind when they say that electrons and neutrinos, rather than being presumptive elements of the scientific image, are directly given to scientists when they use them in interventions. When that is the case, electrons (or whatever entities typically associated with the scientific image) are manifest rather than scientific for these scientists.
} 
science and physics (probably more so than most distinctions), we must accept that, in spite of what scholars - including, arguably, Sellars himself - often make of it, the manifest-scientific distinction does not introduce an epistemological or metaphysical boundary between different kinds of objects and events, but rather a pragmatic boundary between different ways in which we collectively deal with objects and events. In other words, the manifest-scientific distinction can be best understood, not as a metaphysical distinction between apparent and real objects and events, or as an epistemological distinction between perceptible (along with introspectable) and imperceptible objects and events, but rather as a distinction, which is not necessarily rigid over time, between different and recurrent ways in which we collectively deal, in practice, with objects and events. ${ }^{29}$

Although an important aspect of this distinction between our pragmatic dealings with manifest and scientific objects and events is the fact that manifest objects and events, unlike scientific objects and events, make a difference in our practical actions and decisions, not necessarily as isolated individuals but rather as groups of individuals - which insufflates with meaning the collective notions of the manifest and the scientific images of the world, this is not necessarily the only, or even perhaps the most salient, aspect of the distinction.

Open Access This article is distributed under the terms of the Creative Commons Attribution Noncommercial License which permits any noncommercial use, distribution, and reproduction in any medium, provided the original author(s) and source are credited.

\section{References}

Albert, D. (1992). Quantum mechanics and experience. Cambridge: Harvard Univ. Press.

Albert, D. (1996). Elementary quantum metaphysics. In J. Cushing, S. Goldstein, \& A. Fine (Eds.), Bohmian mechanics and quantum theory. Dordrecht: Kluwer.

Albert, D. (2000). Time and Chance. Cambridge: Harvard University Press.

Albert, D., \& Loewer, B. (1988). Interpreting the Many-Worlds interpretation. Synthese, 77, 195-213.

Aune, B. (1990). Sellars' two images of the world. Journal of Philosophy, 87, 537-345.

Boyd, R. (1990). Realism, approximate truth and philosophical method. In W. Savage (Ed.), Minnesota studies in the philosophy of science 14. Minneapolis: Univ. of Minnesota Press.

Boyd, R. (1999). Kinds as the "workmaship of men". In J. Nida-Rumelin (Ed.), Rationalitat, realismus, revision. Berlin: de Gruyter.

Brandom, R. (1995). Making it explicit. Cambridge: Harvard University Press.

Brandom, R. (2002). Tales of the mighty dead. Cambridge: Harvard University Press.

Collins, H., \& Pinch, T. (1993). The golem. Cambridge: Cambridge University Press.

deVries, W. (2005). Wilfred Sellars. Montreal: McGill-Queen's University Press.

\footnotetext{
${ }^{29}$ It may be appropriate at this point to restate this conclusion in a somewhat more nuanced fashion, which those who are not willing yet to leave behind more traditional metaphysical or epistemological approaches to philosophy will probably welcome. The key moral here is either that i) the metaphysical and epistemological interpretations of the manifest-scientific distinction are unacceptable and must therefore be replaced with a pragmatist interpretation of the distinction, or ii) any promising metaphysical or epistemological interpretation of the manifest-scientific distinction must necessarily begin with a pragmatist elucidation of what this distinction stands for. While I am inclined to favor i), I am not ready to completely rule out ii). That is, I cannot dismiss the possibility of developing a pragmatist metaphysics and epistemology. I would like to thank both referees, who were coincidentally directed toward this point, for suggesting the convenience of making the point explicit.
} 
Donagan, A. (1975). Determinism and freedom. In H. Castañeda (Ed.), Action, knowledge and reality: Studies in honor of Wilfrid Sellars. Indianapolis: The Bobbs-Merrill Co.

Dupré, J. (1993). The disorder of things. Cambridge: Harvard University Press.

Eddington, A. (1929). The nature of the physical world. New York: MacMillan.

Feynman, R. (1999). The pleasure of finding things out. New York: Helix Books.

Fine, A. (1984). The natural ontological attitude. In J. Leplin (Ed.), Scientific realism. Berkeley: University of California Press.

Fine, A. (1986). Unnatural attitudes: Realist and instrumentalist attachments to science. Mind, 95, 149179.

Fine, A. (1996). The shaky game. Chicago: The University of Chicago Press.

Fodor, J. (1974). Special sciences. Synthese, 28, 97-115.

Fodor, J. (1997). Special sciences: Still autonomous after all these years. In J. Tomberlin (Ed.), Mind, causation and world. Oxford: Blackwell.

Galison, P. (1987). How experiments end. Chicago: University of Chicago Press.

James, W. (1907). Pragmatism. New York: Longmans, Green, and Co.

Karitzis, A., \& Psillos, S. (2007). The door to Sellars. Metascience, 16, 555-559.

Kitcher, P. (1984). 1953 and all that: a tale of two sciences. The Philosophical Review, 93, 335-373.

Kitcher, P. (1993). The advancement of science. Oxford: Oxford University Press.

Kitcher, P. (2001a). Real realism: the Galilean strategy. The Philosophical Review, 110(2), 151-197.

Kitcher, P. (2001b). Science, truth, and democracy. Oxford: Oxford University Press.

Kuhn, T. (1957). The copernican revolution. Cambridge: Harvard University Press.

Kuhn, T. (1970). The structure of scientific revolutions. Chicago: Univ. of Chicago Press.

Latour, B. (1987). Science in action. Cambridge: Harvard University Press.

Latour, B., \& Woolgar, S. (1979). Laboratory life. Beverly Hills: Sage.

Lipton, P. (1991). Inference to the best explanation. London: Routledge.

Maudlin, T. (1997). Descrying the world in the wave function. The Monist, 80, 3-23.

McDowell, J. (1994). Mind and world. Cambridge: Harvard University Press.

McDowell, J. (2009). Having the world in view. Cambridge: Harvard University Press.

Monton, B. (2006). Quantum mechanics and 3N-dimensional space. Philosophy of Science, 73, 778-789.

Nagel, E. (1961). The structure of science. London: Routledge.

Nagel, T. (1970). The possibility of altruism. Princeton: Princeton University Press.

Nagel, T. (1986). The view from nowhere. New York: Oxford University Press.

Niiniluoto, I. (1987). Truthlikeness. Dordrecht: Reidel.

Parfit, D. (1984). Reasons and persons. Oxford: Clarendon.

Peirce, C. (1878). How to make our ideas clear. Popular Science Monthly, 12, 286-302.

Pickering, A. (1984). Constructing quarks. Chicago: University of Chicago Press.

Potter, V. (1994). On understanding understanding. New York: Fordham University Press.

Psillos, S. (1999). Scientific realism. London: Routledge.

Putnam, H. (1978). Meaning and the moral sciences. London: Routledge.

Putnam, H. (1981). Reason, truth and history. Cambridge: Cambridge University Press.

Putnam, H. (1983). Realism and reason. Cambridge: Cambridge University Press.

Sellars, W. (1956). Empiricism and the philosophy of mind. Reprinted in (1963).

Sellars, W. (1962). Philosophy and the scientific image of man. Reprinted in (1963).

Sellars, W. (1963). Science, perception, and reality. London: Routledge.

van Fraassen, B. (1976). On the radical incompleteness of the manifest image. In F. Suppe \& P. Asquith (Eds.), Proceedings of the PSA (Vol. 2). East Lansing: PSA.

van Fraassen, B. (1980). The scientific image. Oxford: Clarendon.

van Fraassen, B. (1999). The manifest image and the scientific image. In D. Aerts, J. Broekaert, \& E. Mathijs (Eds.), Einstein meets Magritte. Dordrecht: Kluwer.

Wallace, D. \& Timpson, C. (2009). Quantum mechanics on spacetime I: spacetime state realism. British Journal for the Philosophy of Science, Forthcoming.

Weinberg, S. (1994). Dreams of a final theory. New York: Pantheon.

Weston, T. (1992). Approximate truth and scientific realism. Philosophy of Science, 59, 53-74.

Wigner, E. (1967). Symmetries and reflections. Bloomington: Indiana University Press.

Wittgenstein, L. (1969). On certainty. New York: Blackwell.

Worrall, J. (1994). How to remain (reasonably) optimistic: Scientific realism and the "luminiferous ether".

In D. Hull \& M. Forbes (Eds.), Proceedings of the PSA, vol. 1). East Lansing: PSA. 